\title{
O conhecimento do contexto na formação inicial em Educação Física
}

CDD. 20.ed. 370.7

371.12

\author{
Daniel MARCON \\ Amândio Braga dos Santos GRAÇA** \\ Juarez Vieira do NASCIMENTO****
}

${ }^{*}$ Curso de Educação
Física, Universidade
de Caxias do Sul.
**Faculdade de Des-
porto, Universidade do
Porto - Portugal.
${ }^{* * *}$ Centro de Des-
portos, Universidade
Federal de Santa Ca-
tarina.

\section{Resumo}

Ao conhecimento pedagógico do conteúdo (CPC) é atribuída a tarefa de transformar o conhecimento do conteúdo dos professores em conhecimento ensinável e compreensivel pelos alunos em distintos contextos de ensino e aprendizagem. Balizado por esse pressuposto, e apoiado nas proposições da literatura sobre o conhecimento do contexto e sobre o CPC, este ensaio teórico analisou como os conhecimentos sobre a sala de aula (microcontexto), a escola (mesocontexto) e a comunidade (macrocontexto) incidem na construção do CPC dos futuros professores e nos cursos de formação inicial em Educação Física. A literatura e a estrutura dos cursos de formação em Educação Física sugerem que os conhecimentos sobre os meso e macrocontextos, embora importantes, não têm participação significativa na construção do CPC dos futuros professores. Tal como os estudos analisados, sugere-se que os professores-formadores, durante a formação inicial, estimulem a reflexão, a sensibilidade e a criticidade dos futuros professores sobre a influência dos meso e macrocontextos no planejamento, na implementação e na gestão de suas práticas pedagógicas, na interação com e na aprendizagem e formação dos alunos. Além disso, que os cursos de formação inicial em Educação Física reconheçam a importância do conhecimento do contexto na construção do CPC dos futuros professores, o abordem em diferentes disciplinas, sob vários ângulos e por meio de distintas estratégias, e não apenas tragam alunos em idade escolar para a instituição de ensino superior, mas levem os futuros professores para dentro das escolas de Educação Básica desde 0 início do curso. Assim, podem ser ampliadas as possibilidades de construção e desenvolvimento do conhecimento do contexto e, consequentemente, do CPC dos futuros professores de Educação Física, qualificando sua formação acadêmica, docente e profissional.

Palavras-chave: Conhecimento pedagógico do conteúdo; Base de conhecimentos; Conhecimentos docentes; Formação de professores; Práticas pedagógicas.

\section{Introdução}

O conjunto de conhecimentos necessários à atuação docente em diferentes âmbitos de ensino e aprendizagem, no sentido de alcançar os objetivos relacionados à aprendizagem e à formação dos alunos, e que é construído e reconstruído constantemente pelo professor e pelo futuro professor durante a formação inicial e ao longo de toda a carreira docente, é referido por alguns autores ${ }^{1-5}$ como base de conhecimentos para o ensino (do original, em Língua Inglesa, "knowledge base for teaching"). Nos estudos de Cochran et al. ${ }^{4}$, sustentados nas formulações de SHULman ${ }^{1}$ e de Grossman ${ }^{3}$, verifica-se que esse conjunto reúne conhecimentos acerca das características dos alunos, dos conteúdos da matéria de ensino, da pedagogia geral e dos contextos que circundam a aprendizagem, bem como uma compreensão unificada dessas quatro componentes: o conhecimento pedagógico do conteúdo. Considerando a sua natureza integrada e integradora, o conhecimento pedagógico do conteúdo exerce papel central, visto que é aquele que o professor e o futuro professor

utiliza para, a partir dos seus objetivos, da realidade

dos alunos e das características do contexto de ensino 
e aprendizagem, convocar, gerir e fazer interagir os conhecimentos da base de conhecimentos para o ensino, visando à adaptação, à transformação e à implementação do conhecimento do conteúdo a ser ensinado, de modo a torná-lo compreensível e ensinável aos alunos ${ }^{6}$ (p.332).

A descrição dos autores sobre o conhecimento pedagógico do conteúdo contempla os outros componentes da base de conhecimentos e destaca a importância do conhecimento do contexto para a atuação dos professores e dos futuros professores, bem como para o alcance dos objetivos educacionais e de formação dos alunos. Para além de assimilarem os pontos de vista de Shulman $^{1}$ e de Grossman ${ }^{3}$, autores como Cochran et al. ${ }^{4}$, Graber ${ }^{7}$, O'Sullivan e Doutis ${ }^{8}$, RinK $^{9}$, ROVEGNO ${ }^{10-13}$, Rovegno e Dolly ${ }^{14}$, SCHINCARIOL ${ }^{15}$, WHIPPLE ${ }^{16}$, entre outros, sublinham a participação dos aspectos sociais, políticos, culturais e organizacionais do ambiente da sala de aula na maneira como o professor ensina, o que ratifica o relevo e a autonomia do conhecimento do contexto dentro da base de conhecimentos para o ensino.

Dos estudos de Doyle ${ }^{17}$, Grossman ${ }^{18}$, Grossman e MCDonald $^{19}$, RinK ${ }^{9}$, Rovegno ${ }^{12}$, Stran e Curtner-

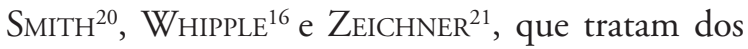
conhecimentos dos professores, podem ser extraídas fortes evidências que ressaltam, veementemente, a necessidade de os cursos de formação inicial prestarem atenção na estrutura do conhecimento do contexto dos futuros professores. Tais evidências encaminham à interpretação de que, inicialmente, se faz necessário o desenvolvimento, por parte dos futuros professores, de uma compreensão aprofundada do contexto particular no qual atuarão, para somente então, adquirirem condiçôes de adaptar os demais integrantes da base de conhecimentos às especificidades do contexto. De modo sintético, a mensagem desses autores é a de que, para serem usados em suas práticas pedagógicas, os conhecimentos dos futuros professores necessitam ser adaptados à especificidade do contexto de ensino e aprendizagem, e muito concretamente, às características circunstanciais do ambiente onde se realizam as aulas, e às peculiaridades de determinado grupo de alunos. $\mathrm{O}$ contexto de ensino e aprendizagem, nesse caso, é formado a partir da interação dos professores com diferentes alunos, que advêm de endereços sociais particulares e se inserem em realidades escolares e de salas de aula específicas.
Durante as décadas de 80 e de 90, o panorama ora analisado foi fortemente influenciado pelas chamadas teorias críticas, que acabaram por desempenhar importante papel no debate relativamente à formação $\mathrm{em}$ e ao ensino da Educação Física no Brasil $^{22-24}$. Não só naquele período, como também nos anos subsequentes e até os dias atuais, algumas dessas propostas teóricas continuaram permeando as discussões na área ${ }^{25-43}$.

A despeito do reconhecimento de tal situação, e ainda que o mote do presente ensaio teórico tenha contornos semelhantes àqueles que sustentam essas propostas teóricas (como, por exemplo, as relações intrínsecas entre as questões culturais, sociais, econômicas e políticas e a formação de professores de Educação Física), cabe ressaltar que elas não constituem tema central de análise neste momento. $\mathrm{O}$ que se pretende, no entanto, é partir dessas mesmas questôes culturais, sociais, econômicas e políticas para analisá-las sob uma ótica ainda pouco explorada na literatura nacional, que diz respeito à teoria da base de conhecimentos para o ensino ("knowledge base for teaching") e, mais especificamente, ao seu integrante conhecimento do contexto. Esse é, precisamente, o ponto que marca a diferenciação entre a literatura que suporta as propostas teóricas críticas e a ênfase do presente ensaio teórico.

Entende-se que o principal objetivo deste ensaio é ampliar a reflexão sobre as possíveis maneiras pelas quais certas questões influenciam na e são influenciadas pela formação de professores de Educação Física. Fundamentalmente, busca-se chamar a atenção para à base de conhecimentos do professor para o ensino, focando no conhecimento do contexto e pedagógico do conteúdo.

Para uma melhor organização das ideias, o presente ensaio divide-se em em duas partes, que se complementam. Na primeira, são apresentadas as proposiçóes da literatura revisada a respeito da estruturação teórica do conhecimento do contexto e sua importância para a formação dos futuros professores de Educação Física. Na segunda, busca-se estabelecer uma relação entre a estruturação teórica do conhecimento do contexto e o conhecimento pedagógico do conteúdo, além de apresentar as possíveis implicações desta relação para os cursos de formação inicial em Educação Física. 


\section{Estruturação teórica do conhecimento do contexto}

Quando o foco é o conhecimento do contexto, SHULMAN ${ }^{1}$ acena com a possibilidade de estruturá-lo em três diferentes âmbitos. Para o autor, a atuação do professor se dá desde o trabalho com os alunos, individualmente, em grupos ou com toda a turma; passa pela administração e gestão escolares; e alcança as particularidades sociais e culturais da comunidade onde se inserem a escola e os alunos. Essa abordagem também é compartilhada por autores como Cochran et al. ${ }^{4}$, Grossman ${ }^{3}$, Grossman e McDoNALD $^{19}$ e ZEICHNER ${ }^{21}$, que analisam o conhecimento do contexto dos professores a partir da sua relação com os alunos, com a escola e com a comunidade.

Além das importantes contribuições desses autores para a compreensão do conhecimento do contexto, é nos estudos de DoyLL ${ }^{17}$ sobre a organização e gestão da sala de aula, de RINK 9 sobre o papel do contexto na aprendizagem docente, e de SIEDENTOP ${ }^{44}$ sobre a perspectiva ecológica da sala de aula, que essa intrincada rede de relaçôes - estabelecida nas situações reais de ensino e aprendizagem - adquire estrutura, consistência e relevância para a investigação relacionada ao processo de formação inicial de professores de Educação Física. Mesmo vinculadas ao contexto das aulas, da sala de aula, do processo de ensino e aprendizagem e da interação dos alunos entre si e com os professores, é importante a consideração das proposiçôes dos autores na esfera do conhecimento do contexto.

Ao analisar os processos de organização e de gestão da sala de aula, Doyle ${ }^{17}$ destaca o próprio ambiente onde são desenvolvidas as aulas, no que tange às várias circunstâncias imediatas que afetam a natureza da ordem e da atuação do professor. De acordo com o autor, as características intrínsecas do contexto da sala de aula: "simultaneidade, multidimensionalidade, imediaticidade, imprevisibilidade, e caráter público e histórico"17 (p.394-5, tradução nossa), já estão em vigor antes mesmo de os professores e os alunos chegarem à sala de aula. São esses elementos que estruturam o cenário no qual se desenvolve a aula, impondo pressões que modelam a tarefa de ensinar e que exigem intervenção qualificada por parte do professor.

Nessa esteira, RINK ${ }^{9}$ esclarece que os professores, em especial os de Educação Física,

necessitam ensinar uma ampla variedade de conteúdos para uma ampla gama de alunos (de diferentes idades, gêneros, etnias, orientações culturais, habilidades, e experiências) em contextos muito diversos e com quantidades variáveis de apoio. Alunos e professores de uma mesma classe provavelmente responderão de diferentes maneiras em diferentes momentos, dependendo do seu contexto social e do que está acontecendo em suas vidas pessoais em um dado período. O ensino não é apenas complexo, mas é também realizado em ambientes muito diversos e dinâmicos (p.17, tradução nossa). Em sintonia com as abordagens de Doyle ${ }^{17}$ e de RINK $^{9}$, SiEDENTOP ${ }^{44}$ também destaca a necessidade de desenvolvimento do conhecimento do contexto dos futuros professores de Educação Física, ao explicar que o ensino não se parece com a preparação para um jogo ou um recital, como uma palestra ou um seminário na universidade. Os professores ministram aulas o dia todo, cinco dias por semana, e durante todo o ano letivo. Professores e alunos têm que viver juntos e pacificamente por todas as aulas, ao longo do ano escolar ${ }^{44}$ (p.428, tradução nossa).

Esse amplo leque de responsabilidades que recai sobre o professor de Educação Física recebeu atenção de Ramos et al. ${ }^{45}$. Assim como para Doyle ${ }^{17}$, RINK ${ }^{9} \mathrm{e}$ SieDENTOP ${ }^{44}$, a atuação docente do professor de Educação Física, na perspectiva desses autores, também se caracteriza como multidimensional, imprevisível e com "simultaneidade de situaçôes, cada qual com uma dinâmica própria, exigindo do professor procedimentos complexos", que atendam às "características circunstanciais e inesperadas dos eventos e das particularidades dos contextos", seja dos alunos e da sala de aula, seja da escola e da comunidade ${ }^{45}$ (p.1).

A reflexão estabelecida a partir dos estudos dos diferentes autores apresentados, além de dar melhor entendimento ao conhecimento do contexto na formação dos futuros professores de Educação Física, também permite o retorno à própria proposta de SHULMAN ${ }^{1}$, relativamente à genealogia da base de conhecimentos para o ensino. Sendo assim, e de modo a orientar a análise neste ensaio, aqueles três âmbitos do conhecimento do contexto foram denominados, respectivamente, microcontexto, da sala de aula, mesocontexto, da escola, e macrocontexto, da comunidade, sendo todos considerados sob o ponto de vista da formação inicial e de seus reflexos na qualificação docente dos futuros professores de Educação Física.

O conhecimento do microcontexto pode ser delimitado pelo conhecimento que os futuros professores necessitam desenvolver a respeito das especificidades inerentes ao ambiente aberto, complexo, dinâmico e multifacetado da sala de aula, e a exigência que se lhes impõe de gerir todas essas questóes no sentido da 
aprendizagem e da formação dos alunos. Portanto, o espaço da sala de aula e todas as relações estabelecidas com os alunos, com o conteúdo da matéria de ensino e com as estratégias pedagógicas, bem como seus reflexos para o processo de ensino e aprendizagem, se enquadram no âmbito do microcontexto.

No caso particular da Educação Física, também se inserem no conhecimento do microcontexto dos futuros professores as experiências e as concepções que os alunos têm relativamente a diferentes temas, por exemplo, atividades físicas, esportivas, recreativas, culturais e de lazer; educação, saúde, bem-estar e qualidade de vida, assim como as respectivas dificuldades e virtudes, os interesses e as necessidades que os alunos manifestam sobre cada um dos temas abordados em aula.

Com o desenvolvimento do conhecimento do contexto dos futuros professores de Educação Física nessa direção, espera-se que eles sejam capazes de balizar sua atuação docente a partir das peculiaridades do próprio ambiente da sala de aula, e considerar atenta e conscientemente as expectativas quanto ao exercício do seu papel de professor.

$\mathrm{O}$ conhecimento do mesocontexto envolve não apenas as concepções pedagógicas, epistemológicas, de avaliação, de aluno, de sociedade e de mundo que os futuros professores têm e que a escola apresenta em seu projeto pedagógico, mas, fundamentalmente, a incidência de todas essas concepções no planejamento, na implementação e na gestão de suas práticas pedagógicas e, principalmente, na aprendizagem e na formação dos alunos.

No que concerne especificamente à área de estudo da Educação Física, e, semelhantemente ao âmbito do microcontexto, o conhecimento do mesocontexto considera as concepçôes que o projeto pedagógico, os professores (de Educação Física e das demais disciplinas curriculares), a comunidade escolar e os próprios dos futuros professores apresentam, por exemplo, sobre questóes como atividades físicas, esportivas, recreativas, culturais e de lazer e sobre temas como educação, saúde, bem-estar e qualidade de vida. Em sua essência, o conhecimento do mesocontexto dos futuros professores diz respeito à magnitude da participação de todas essas concepções no planejamento, na implementação e na gestão de suas práticas pedagógicas, bem como na aprendizagem e na formação dos alunos.

O conhecimento do macrocontexto se refere às condiçōes e aos níveis educacionais, culturais, sociais, econômicos, de qualidade de vida e de acesso à saúde, ao esporte, à cultura e ao lazer da comunidade onde está inserida a escola e onde vivem os alunos e suas famílias. É fundamental que os futuros professores de Educação Física não apenas conheçam tal realidade, mas que a contemplem quando planejam, implementam e gerem suas práticas pedagógicas, assim como no convívio com os alunos e com a comunidade escolar. Adicionalmente, é necessário que reflitam sobre a maneira pela qual o aprendizado dos alunos é incorporado no seu estilo de vida, repercute no seu dia a dia e influencia na melhoria da qualidade vida deles próprios, de suas famílias e de sua comunidade.

Um viés do conhecimento do macrocontexto dos futuros professores de Educação Física vai em direção à sua área de estudo e de docência, de modo a estarem atentos às novidades, às oportunidades $\mathrm{e}$ às restrições impostas por ela à sua atuação docente e profissional. Além disso, uma interpretação ainda mais alargada, e que representa parte significativa do conhecimento do macrocontexto, diz respeito, por exemplo, às dimensões governamentais, institucionais e políticas; às forças sociais, culturais e acadêmicas; aos meios de comunicação social; e às Instituições de Ensino Superior (IES). Todos esses segmentos do macrocontexto influenciam, em maior ou menor medida, no sistema educativo - desde as esferas local e municipal até as esferas estadual e nacional - e nos diferentes níveis de ensino - desde a Educação Básica até o Ensino Superior.

Os futuros professores de Educação Física necessitam não apenas conhecer as peculiaridades de cada um desses três âmbitos do conhecimento do contexto, como também considerá-las cuidadosa e criteriosamente nas práticas pedagógicas por eles planejadas, implementadas e geridas. Espera-se, inclusive, que eles participem, organizem, promovam e se engajem em diferentes iniciativas, projetos, atividades e eventos, seja na área de Educação Física ou na área de outras disciplinas curriculares, seja na escola ou na comunidade.

O conhecimento do contexto adquire caráter específico e imprescindível tanto como um dos componentes da base de conhecimentos para o ensino quanto na formação dos futuros professores de Educação Física. Isso devido ao fato de o conhecimento do contexto provir do contato, da experiência e da relação direta e concreta em diferentes facetas: a) com os papéis e as responsabilidades que necessitarão assumir; b) com a realidade da escola, suas rotinas, tarefas e normas; e c) com as dinâmicas inerentes à interação dos diferentes atores escolares, sejam eles os alunos, os professores, os coordenadores, os diretores ou os funcionários técnico-administrativos, ou os pais dos alunos.

Quanto maior for a proximidade e o conhecimento sobre o contexto de vida dos alunos e de 
suas comunidades, e sobre o ambiente escolar e de realização das aulas, de mais elementos os futuros professores disporão tanto para planejar, implementar e gerir suas práticas pedagógicas quanto para alcançar distintos objetivos, seja da disciplina de Educação Física para com os alunos, seja dos alunos para com as aulas de Educação Física.

Parece inevitável que, na análise isolada de quaisquer desses três âmbitos do conhecimento do contexto, acabem por emergir também os demais, à medida que todos se relacionam intrinsecamente, se perpassam, interagem continuamente e se complementam para constituir a individualidade do contexto de vida de cada aluno, de cada sala de aula, de cada escola e de cada comunidade. Dita relação fica evidente, ainda, uma vez que as características da comunidade influenciam nos conhecimentos e nas concepções dos alunos, os quais, individual e coletivamente, reverberam esses conhecimentos e essas concepções de volta para a própria comunidade, numa relação recíproca que pode, ou não, ser mediada pela escola e pelos professores.

MeNCK $^{46}$ confirma e aprofunda essa reflexão ao indicar que o microcontexto não é ele em si, mas apenas uma representação simbólica da realidade e, portanto, dos meso e macrocontextos. Para o autor, a atuação docente do professor pressupóe interpretar essa realidade e considerá-la em todas as situações de ensino e aprendizagem que estiverem sob sua responsabilidade.

Há que se reconhecer, também, a dificuldade em separar claramente os diferentes âmbitos do conhecimento do contexto, visto que suas fronteiras muitas vezes se diluem umas nas outras. Exemplo disso são os pais dos alunos, que podem, por um lado, apenas fazer parte da comunidade que circunda a escola, inserindo-se, portanto, mais no macrocontexto. Por outro lado, os pais podem conviver mais proximamente dos professores e do ambiente escolar e, até mesmo, participar da gestão escolar como representantes da comunidade, inserindo-se, nesse caso, mais no mesocontexto.

Considerando os elementos analisados, percebese que o desenvolvimento dos conhecimentos dos futuros professores de Educação Física sobre cada um dos micro, meso e macrocontextos reverterá em benefício da sua intervenção pedagógica com os alunos, potencializando o alcance dos objetivos educacionais e de formação dos próprios alunos e qualificando, consequentemente, sua própria formação inicial e atuação docente e profissional.

\section{Relações entre os conhecimentos do contexto e pedagógico do conteúdo na formação inicial em Educação Física}

A análise anterior traz implícita a relação recíproca e interdependente estabelecida entre esses dois integrantes da base de conhecimentos para o ensino: conhecimento do contexto e conhecimento pedagógico do conteúdo. Mais especificamente, e conforme afirmam diferentes autores ${ }^{1,3-5,47-50}$, é a partir da estruturação e do gradativo aperfeiçoamento do conhecimento do contexto que serão alcançadas algumas das condições necessárias para que, durante a sua formação inicial, os futuros professores construam e desenvolvam aquele que é considerado o componente nuclear do conhecimento para a docência: o conhecimento pedagógico do conteúdo. A importância dessa relação é sublinhada por diferentes autores ${ }^{7,10-13,15-16}$ e sintetizada por VEAL e MAKINSTER $^{51}$, quando descrevem o conhecimento pedagógico do conteúdo como sendo a

capacidade de traduzir o conteúdo da matéria de ensino para um diversificado grupo de alunos usando múltiplas estratégias e métodos de ensino e de avaliação, levando em consideração as limitações contextuais, culturais e sociais do ambiente de aprendizagem (p.11, tradução nossa).

Ao longo da Educação Básica, os alunos desenvolvem um sistema de crenças e de concepções e um conjunto de conhecimentos elementares a respeito da instituição escola, da profissão docente e do papel de professor, além de temas como, por exemplo, educação, ensino, aprendizagem, esporte, lazer, saúde e qualidade de vida. Todas essas crenças, concepçôes e conhecimentos são incorporados à base de conhecimentos para o ensino dos futuros professores, com a qual ingressam na formação inicial em Educação Física $^{15-16,52-59}$. Esses podem ser considerados alguns dos elementos estruturantes do próprio conhecimento do contexto dos futuros professores, e que começam a delinear cada um dos seus conhecimentos no âmbito dos micro, meso e macrocontextos.

Apesar de serem importantes para a constituição da identidade docente e profissional dos futuros professores, esses conhecimentos, por terem sido construídos alguns anos antes, ainda estarem desorganizados 
e serem relativamente incipientes, não oferecem plenas condições de embasar o planejamento, a implementação e a gestão de suas práticas pedagógicas. Dadas as especificidades que diferenciam o contexto da Educação Básica no qual conviveram como alunos daquele no qual atuarão como professores em formação, se fazem necessárias uma reaproximação e uma releitura desse contexto por parte dos futuros professores.

Muitas vezes, por não conviverem na mesma região onde se situa a escola, os futuros professores têm dificuldade para compreender a cultura do bairro do qual os alunos fazem parte, o que reforça a necessidade de se apropriarem daquela realidade para poderem intervir adequadamente naquele contexto. Conforme explicam autores como DOYLE ${ }^{17}$, RINK ${ }^{9}$, ROVEGNO ${ }^{12}$, ROVEGNO e DOLLY $^{14}$, SCHINCARIOL ${ }^{15}$, WhiPpleE ${ }^{16}$, WitTizORECKI et al. ${ }^{60} \mathrm{e}$ ZEICHNER ${ }^{21}$, éfundamental que os futuros professores entendam a realidade de vida e a comunidade de onde vêm os alunos, de modo a compreenderem quais são e como se estruturam as concepçôes e as eventuais concepções equivocadas que os alunos trazem consigo para o ambiente de ensino e aprendizagem.

Em outras situaçōes, a disparidade entre as condições de vida dos futuros professores e da comunidade escolar se refere não apenas a regiōes geográficas, mas também, por exemplo, a níveis culturais e socioeconômicos, o que destaca ainda mais a importância de que eles observem essas questôes na sua inserção nos contextos escolar e de vida dos alunos , $^{9} 12-14,17-18,21,61-62$. Nesses casos, as características específicas do novo contexto de ensino e aprendizagem impõem desafios peculiares aos futuros professores, os quais implicarão, invariavelmente, a readequação dos distintos conhecimentos construídos até então.

É justamente por isso que, ao serem programadas práticas pedagógicas com alunos em idade escolar, e principalmente nos períodos que antecedem os estágios curriculares, os professores-formadores, bem como os próprios cursos de formação inicial em Educação Física, normalmente, dedicam grande atenção à leitura da realidade do contexto de estágio, ou de prática pedagógica, por parte dos futuros professores. $\mathrm{Ou}$ seja, espera-se que os futuros professores obtenham informaçōes específicas daquela comunidade e daquela escola, em particular, e daqueles alunos, em especial.

De fato, essa aproximação com os alunos e com as escolas, agora com o olhar de professores em formação, contribui, sobremaneira, para a coleta e análise de informaçôes relevantes e imprescindíveis para o planejamento, a implementação e a gestão das práticas pedagógicas, relativas, justamente, aos micro, meso e macrocontextos que compõem o cenário da premente intervenção docente. Esse momento é importante, ainda, para que os futuros professores desmistifiquem algumas de suas tradicionais apreensões concernentes ao perfil e às características da escola em que atuarão e tenham atendidas as suas expectativas de saber quem e como são os alunos, de modo a se ampliarem as possibilidades de sucesso de sua intervenção docente naquela realidade.

Todas essas preocupaçōes dos professores-formadores e dos programas de formação se justificam, portanto, pelo reconhecimento da necessidade de que a realidade dos micro, meso e macrocontextos seja conhecida, assimilada e absorvida pelos futuros professores, de tal maneira que se alcance o principal objetivo com todo esse processo: as efetivas consideração e incorporação desses três âmbitos do conhecimento do contexto no planejamento, na implementação e na gestão de suas práticas pedagógicas, bem como no convívio com os alunos e com as comunidades escolar e extraescolar. Essa é a direção para onde apontam as proposições de diferentes autores ${ }^{7-9,12-13,15-18,21,42,60,62-63}$.

Embora possam fazer parte do cotidiano dos professores da Educação Básica e serem incorporadas no seu fazer pedagógico - conforme demonstram diferentes estudos $^{41,62,64-65}$ - e apesar do apreço e da valorização de todas essas questôes para a formação docente dos futuros professores de Educação Física, os resultados da investigação realizada por $\mathrm{MARCON}^{66}$ colocam em xeque a viabilidade do alcance desses objetivos no interior dos cursos de formação inicial. O autor concluiu que futuros professores de diferentes etapas da formação inicial em Educação Física, quando ministram diferentes modalidades de práticas pedagógicas e estágios curriculares, ignoram contextos mais amplos como o escolar e o de vida dos alunos, justamente pela grande atenção que dedicam ao microcontexto da sala de aula, à sua relação direta com os alunos e aos resultados imediatos das suas intervençóes pedagógicas.

Esses resultados fazem eco às proposições de Mondéjar e ÁlLVAREZ ${ }^{67}$, quando afirmam que os futuros professores parecem ter problemas mais urgentes para resolver ao ministrarem suas práticas pedagógicas e seus estágios curriculares, como, por exemplo, o aumento do nível de autopercepção de competência pela conquista da autonomia e da confiança, do respeito e do reconhecimento dos alunos. Preocupações exacerbadas com essas questôes poderiam impedir os futuros professores de desviar o olhar para fora do microcontexto da própria aula e lançá-lo para o mesocontexto da escola e, menos ainda, para o macrocontexto da comunidade. 
As conclusões desses autores corroboram os resultados dos estudos de ZEICHNER ${ }^{21}$, quando explica que, "por terem tendência a trabalhar com um professor de cada vez, numa sala de aula isolada”, os futuros professores "ficam com a ideia de que o ensino é uma atividade solitária", e se inserem "nas salas de aula como se o resto da escola não existisse" (p.59). Nesse caso, a ênfase da formação inicial de professores "somente à instrução de crianças numa sala de aula não prepara os professores para a série de responsabilidades e para os papéis de chefia que irão desempenhar" (p.60). De acordo com esse autor, apesar de alguns programas de formação inicial tentarem "acabar com este isolamento e incentivar o 'ensino em pares' ou a 'supervisão mútua entre alunos-mestres', muito poucas dessas propostas expandem a prática pedagógica dos futuros professores "para além do domínio da sala de aula, com vistas a incluir uma atenção especial à escola e à comunidade" (p.60).

Assim como MarCon ${ }^{66}$, MondéJAr e Álvarez ${ }^{67}$ e ZEICHNER ${ }^{21}$, ROVEGNO ${ }^{13}$ também analisa criticamente essas questóes. Focando o processo de formação inicial de professores de Educação Física especificamente na realidade norte-americana, a autora explica que, provavelmente, a principal dificuldade encontrada pelos programas de formação inicial de professores seja a de como modificar as crenças de futuros professores que têm atitudes e posturas sexistas, racistas e homofóbicas; são preconceituosos com pessoas com sobrepeso; e estão interessados em trabalhar somente com bons atletas e em programas que envolvam apenas alunos sem qualquer deficiência ${ }^{13}$ (p.89, tradução nossa).

Nesses casos, é provável que os futuros professores idealizem características, interesses e necessidades dos seus alunos baseados em padrões estereotipados de motivação, envolvimento, habilidade e rendimento, os quais acabam por condicionar o planejamento, a implementação e a gestão de suas práticas pedagógicas, independentemente das reais especificidades dos micro, meso e macrocontextos. Por isso, o conhecimento do contexto, essencialmente nos seus âmbitos meso e macro, parece participar superficialmente da rotina acadêmica dos futuros professores e, consequentemente, assumir posição periférica tanto dentro da base de conhecimentos para o ensino quanto na construção do seu conhecimento pedagógico do conteúdo.

Como agravante, os programas de formação e a própria literatura parecem não enfocar direta $\mathrm{e}$ especificamente o conhecimento do contexto, na formação inicial de professores de Educação Física, sob a perspectiva de ser ele um dos integrantes da base de conhecimentos para o ensino e de contribuir para a construção do conhecimento pedagógico do conteúdo dos futuros professores.

Refletindo sobre a inserção do conhecimento do contexto nos programas de formação inicial em Educação Física, RINK ${ }^{9}$, RovegnO ${ }^{12-13}$ e STRAN e CURTNER$\mathrm{S}_{\mathrm{MITH}}{ }^{20}$ chamam a atenção para a necessidade de se analisar a maneira pela qual os projetos pedagógicos dos cursos contemplam o ensino dessa disciplina para alunos em diferentes idades; promovem a melhora do ensino, do prazer, da motivação e da participação dos alunos em programas de atividades físicas, esportivas e de lazer, dentro e fora da escola; e consideram as perspectivas e as expectativas dos alunos, o que eles avaliam como significativo e estimulante ou como pouco significativo e muito desestimulante.

Embora amplamente exploradas nos últimos 20 anos, especialmente por vertentes educacionais críticas da Educação Física ${ }^{22-43}$, a contextualização da formação de professores raramente foi analisada especificamente sob o prisma da base de conhecimentos para o ensino ("knowledge base for teaching") e, particularmente, no que respeita à essência do seu integrante conhecimento do contexto. Ou seja, a literatura parece não ter disponibilizado maior detalhamento quanto à importância e ao papel desempenhado pelo conhecimento do contexto - fundamentalmente nos seus âmbitos meso e macro - na formação inicial dos futuros professores, na sua interpretação como um dos componentes fundamentais desse conjunto de conhecimentos necessários à docência.

Conforme explicam Ferraz e Correia ${ }^{43}$, O'Sullivan e DOUTIS $^{8}$ e ZEICHNER ${ }^{21}$, a investigação sobre o ensino ignora, no sentido mais abrangente do termo, os contextos político e social nos quais os professores atuam e ensinam as crianças, seja dentro, seja fora da sala de aula. A análise das revisões de ABELl et al. ${ }^{68}$ e de VAN DRIEL et al. ${ }^{69}$ também permite concluir que o peso exercido pelo conhecimento do contexto, seja como mais um dos integrantes da base de conhecimentos para o ensino, seja para a construção do conhecimento pedagógico do conteúdo, é muito inferior àquele exercido, por exemplo, pelo conhecimento do conteúdo da matéria de ensino.

Em sua crítica sobre a falta de objetividade da literatura na abordagem dessas questôes contextuais, bem como sobre as bases que sustentam os programas de formação de professores, Grossman e MCDONALD ${ }^{19}$ explicam que,

embora não sejam recentes os argumentos de que os programas de formação de professores necessitam ser concebidos de maneira contextualizada, são escassas as investigações que analisam a formação inicial sob 
esse ponto de vista. No campo da formação de professores, são relativamente poucas as pesquisas que têm investigado a maneira pela qual os contextos mais amplos, relativos às políticas educacionais, às características das escolas de Educação Básica e às demandas do mercado de trabalho se inter-relacionam e se inserem nos contextos específicos das IES para arquitetar os projetos de curso dos programas de formação de professores. A restrita consideração de tais fatores contextuais tornou difícil tanto para os programas de formação reunir seus elementos estruturantes quanto para os educadores e legisladores extrapolar questôes relativas unicamente às demandas locais (p.194, tradução nossa).

Mesmo reconhecendo alguns indícios de avanço nesse sentido, Ball e ForZani ${ }^{70}$, Ferraz e Correia ${ }^{43}$, RINK $^{9}$ e ROVEGNO ${ }^{12-13}$ também advertem para a necessidade de se conhecer, pormenorizadamente, como todas essas relações acontecem e como incidem na formação dos futuros professores, na atuação docente dos professores e no aprendizado e na formação dos alunos da Educação Básica.

Por não ser considerado e analisado em profundidade, nem pelos programas de formação inicial em Educação Física, nem pela literatura da área, SCHINCARIOL ${ }^{15}$ afirma que "não é de se estranhar que o desenvolvimento do conhecimento do contexto não faça parte das prioridades dos programas de formação inicial para a formação docente dos futuros professores" (p.258, tradução nossa).

Mesmo diante dessas evidências, há que se destacar que o conhecimento do contexto desempenha papel essencial no processo de formação inicial dos futuros professores de Educação Física, uma vez que é inerente ao e representa a consolidação da proposta do conhecimento pedagógico do conteúdo. Em outras palavras, quando se amalgamam os âmbitos micro, meso e macro do conhecimento do contexto, é estruturado o cenário que viabiliza a catálise dos demais integrantes da base de conhecimentos para o ensino, nomeadamente, os conhecimentos dos alunos, do conteúdo e pedagógico geral, redundando na evolução do conhecimento pedagógico do conteúdo dos futuros professores. Nessa perspectiva, o conhecimento do contexto não é considerado um fim, mas um meio para que os programas de formação inicial alcancem a construção do conhecimento pedagógico do conteúdo e a formação docente dos futuros professores de Educação Física.

De fato, o posicionamento crítico dos autores analisados sugere que o efetivo desenvolvimento do conhecimento do contexto dos futuros professores somente ocorrerá quando eles puderem explorar e interagir diretamente com o contexto, convivendo diuturnamente e durante um período prolongado, com o microcontexto, quer da sala de aula, sua organização e gestão, quer dos alunos, suas características, concepções, interesses e necessidades; com o mesocontexto da escola e dos demais professores, suas concepçôes, crenças e conhecimentos; e com o macrocontexto da comunidade, a inter-relação e as possibilidades de a comunidade participar do contexto escolar e viceversa. Nessa esteira, quando analisam o processo de formação inicial de professores de Educação Física, Stran e Curtner-SMith ${ }^{20}$ advertem, inclusive, que "ensinar em tempo integral na mesma escola por várias semanas é muito diferente que ensinar uma ou duas horas por [algumas] semana[s] em diferentes escolas" (p.253, tradução nossa).

Dada a dificuldade de montar esse cenário e de alcançar todos esses objetivos dentro do período de realização do curso, pode-se inferir, até mesmo, que a verdadeira evolução do conhecimento do contexto dos futuros professores não se dê no interior dos programas de formação inicial em Educação Física. As possibilidades de desenvolvimento desse conhecimento somente seriam conseguidas, efetivamente, depois que os futuros professores concluíssem sua formação inicial e se inserissem, como professores de Educação Física, em escolas de Educação Básica.

Essas ilações não retiram os programas de formação inicial em Educação Física do centro do processo, não os eximem da responsabilidade de planejar e de implementar, ao longo de todo o curso e não somente nos estágios curriculares, diferentes modalidades de práticas pedagógicas. Conforme destacam autores como Behets e Vergauwen ${ }^{71}$, Doyle ${ }^{17}$, Ferraz e Correia $^{43}$, Grossman ${ }^{18}$, Metzler et al. ${ }^{72}$, Molina Neto $^{61}$, O'Sullivan e Doutis ${ }^{8}$, RinK $^{9}$, Rovegno ${ }^{12-13}$, SCHINCARIOL ${ }^{15}$, WhiPPLE ${ }^{16}$, WitTIZORECKI e Molina NETO $^{62}$ e ZEICHNER ${ }^{21}$, é necessário que os programas de formação inicial levem os futuros professores a um esclarecimento sobre a maneira pela qual a complexidade das estruturas sociais incide no processo de aprendizagem dos alunos, bem como sobre a natureza contextual que divisa as várias instâncias de ensino das diferentes disciplinas curriculares (incluindo a Educação Física) como, por exemplo, escolas na cidade, na periferia e na zona rural, escolas públicas e privadas, Educação Infantil e Ensino Médio.

Estudos recentes ${ }^{12,16,19,43,73-76}$ dão conta, ainda, de que essa é a direção para onde a investigação relacionada à formação inicial de professores tende a caminhar rapidamente. Para os autores, a investigação 
nessa área estreitará fortemente a conexão entre a formação inicial de professores nas IES e a atuação dos professores na Educação Básica, e subsidiará a ampliação das possibilidades de construção e de desenvolvimento do conhecimento do contexto, e consequentemente do conhecimento pedagógico do conteúdo e da base de conhecimentos para o ensino, dos futuros professores dentro dos próprios programas de formação inicial, seja em Educação Física, seja nas outras disciplinas curriculares.

As análises realizadas a partir da literatura consultada indicam que o conhecimento do contexto, apesar de sua importância, não é claramente contemplado como um objetivo para a formação inicial dos futuros professores de Educação Física, seja pela literatura da área, seja pelos próprios programas de formação.

Mesmo que a construção dos conhecimentos sobre a docência dos futuros professores seja de longo prazo e se dê por meio de uma complexa e diversificada rede de experiências e de situaçôes de ensino e aprendizagem, tornar-se capaz de demonstrar determinado conhecimento em um contexto específico não significa, necessariamente, possuir as mesmas habilidades para demonstrá-lo em outro contexto, com outras características. Nesse caso, a transposição de preocupações voltadas exclusivamente ao microcontexto para preocupações mais amplas, relacionadas aos meso e macrocontextos, não constitui processo simples, nem que ocorre naturalmente. A revisão de diferentes estudos sugere que, por conta própria, os futuros professores apresentam grandes dificuldades para alcançar essa transposição, requerendo, pois, a intervenção cuidadosa, qualificada e incisiva dos professores-formadores.

Os futuros professores de Educação Física somente poderão atentar para, refletir sobre e considerar os três âmbitos do seu conhecimento do contexto por meio de diversificadas estratégias que, desenvolvidas ao longo da formação inicial, lhes ofereçam a oportunidade de se aproximar, conhecer, analisar, questionar e interagir com os contextos educacional e de vida dos alunos. São exemplos dessas estratégias as distintas modalidades de práticas pedagógicas, as quais são planejadas e ministradas para os colegas e, principalmente, para alunos em idade escolar; planejadas, discutidas e refletidas com os colegas e com os professores-formadores; e realizadas na IES e em escolas de Educação Básica ${ }^{77}$.

Os programas de formação inicial em Educação Física necessitam, portanto, reconhecer a importância do conhecimento do contexto tanto como um dos integrantes da base de conhecimentos para o ensino quanto no processo de construção do conhecimento pedagógico do conteúdo dos futuros professores, abordá-lo em diferentes disciplinas, sob vários ângulos e por meio de distintas estratégias e, efetivamente, não apenas trazer os alunos em idade escolar para a IES, mas e fundamentalmente, levar os futuros professores para dentro de escolas de Educação Básica desde o início do curso.

Espera-se que os professores-formadores, ao longo de toda a formação inicial, estabeleçam mecanismos para estimular a reflexão, a sensibilidade e a criticidade dos futuros professores a respeito da influência dos meso e macrocontextos no planejamento, na implementação e na gestão de suas práticas pedagógicas, na sua interação com os alunos e, sobretudo, na aprendizagem e na formação dos próprios alunos. Assim, serão potencialmente ampliados tanto a valorização do conhecimento do contexto dentro da base de conhecimentos para o ensino quanto o reconhecimento da sua relação indissociável com e o peso de sua influência no processo de construção do conhecimento pedagógico do conteúdo dos futuros professores de Educação Física.

Em síntese, acredita-se que, desse modo, sejam ampliadas as possibilidades de que os programas de formação inicial aperfeiçoem os processos de construção, de desenvolvimento e de estruturação da base de conhecimentos para o ensino e, consequentemente, do conhecimento do contexto e do conhecimento pedagógico do conteúdo dos futuros professores de Educação Física, qualificando, assim, a sua formação acadêmica, docente e profissional.

\begin{abstract}
Context knowledge in the initial training in physical education

Pedagogical content knowledge is conceived as responsible for transforming the content knowledge of teachers in knowledge teachable and understandable by students in different contexts of teaching and learning. Considering this assumption, and supported in the proposals of the literature, this theoretical study examined how knowledge about classroom (micro context), school (meso context) and community
\end{abstract}


(macro context) participate in the construction of pedagogical content knowledge of prospective teachers, and in training programs in Physical Education. The information reviewed suggests that knowledge about meso and macro contexts, although very important, do not have meaningful participation in the construction of pedagogical content knowledge for prospective teachers, and is not clearly contemplated as a goal for the initial training in Physical Education, neither by literature of the field, nor by their own training programs. In line with the studies reviewed, we suggested that teachers-trainers, during initial training, stimulate reflection, sensitivity and criticality of prospective teachers about the influence of meso and macro contexts in planning, implementation, and management of teaching practices, in interaction with and in learning and training of students. We believe, therefore, are enlarged the possibilities of construction and development of the context knowledge and, consequently, the pedagogical content knowledge for prospective Physical Education teachers, qualifying their academic, teaching and professional training.

KEY WORDS: Pedagogical content knowledge; Knowledge base for teaching; Teaching knowledge; Teaching formation; Teaching practices.

\section{Referências}

1. Shulman, L. S. Knowledge and teaching: foundations of the new reform. Harvard Educ Rev. 1987;57:1-27.

2. Grossman P, Wilson S, Shulman L. Teacher of substance: subject matter knowledge for teaching. In: Reynolds M, organizer. Knowledge base for the beginning teacher. New York: Pergamon; 1989. p.23-36.

3. Grossman P. The making of a teacher: teacher knowledge and teacher education. New York: Teachers College Press; 1990.

4. Cochran KF, King RA, Deruiter JA. Pedagogical content knowledge: a tentative model for teacher preparation. In: Annual Meeting of the American Educational Research Association; 1991; Chicago, US. Chicago: American Educational Research Association; 1991.

5. Graça A. O conhecimento pedagógico do conteúdo no ensino do basquetebol [tese]. Porto (PT): Universidade do Porto, Faculdade de Desporto; 1997.

6. Marcon D, Graça ABS, Nascimento JV. Reinterpretação da estrutura teórico-conceitual do conhecimento pedagógico do conteúdo. Rev Bras Educ Fís Esporte. 2011;25:323-39. [citado 1 ago. 2011]. Disponível em: http://www.scielo. br/pdf/rbefe/v25n2/13.pdf.

7. Graber KC. The influence of teacher education programs on the beliefs of student teachers: general pedagogical knowledge, pedagogical content knowledge, and teacher education course work. J Teach Phys Educ. 1995;14:157-78.

8. O' Sullivan M, Doutis P. Research on expertise: guideposts for expertise and teacher education in physical education. Quest. 1994;46:176-85.

9. Rink JE. Teacher education programs: the role of context in learning how to teach. J Phys Educ Recreat Dance. 1997;68:17-24.

10. Rovegno I. Teaching within a curricular zone of safety: school culture and the situated nature of student teachers' pedagogical content knowledge. Res Q Exerc Sport. 1994;65:269-79.

11. Rovegno I. Theoretical perspectives on knowledge and learning and a student teacher's pedagogical knowledge of dividing and sequencing subject matter. J Teach Phys Educ. 1995;14:284-304.

12. Rovegno, I. Situated perspectives on learning. In: Kirk D, MacDonald D, O'SULLIVAN M, organizers. The handbook of physical education. London: Sage; 2006. p.262-74.

13. Rovegno I. Learning and instruction in social, cultural environments: Promising research agendas. Quest. 2008;60:84-104.

14. Rovegno I, Dolly JP. Constructivist perspectives on learning. In: Kirk D, MacDonald D, O'Sullivan M, organizer. The handbook of physical education. London: Sage; 2006. p.242-61.

15. Schincariol LM. The types, sources, and perceived relevance of knowledge acquisition, and the enacted effects when teaching unfamiliar and familiar physical education content [tese]. Columbus (OH): The Ohio State University; 2002. [citado 25 mar. 2008]. Disponível em: http://proquest.umi.com/pqdweb?did=765251041\&sid=5\&Fmt=2\&clientId $=37541 \& \mathrm{RQT}=309 \& \mathrm{VName}=\mathrm{PQD}$. 
16. Whipple CE. Preservice teachers' views of content and pedagogical knowledge presented in the elementary component of a physical education teacher education program. [tese]. Columbus (OH): The Ohio State University; 2002. [citado 10 set. 2009]. Disponível em: http://proquest.umi.com/pqdweb?did=764690441\&sid=4\&Fmt=2\&clientId=37541\&RQT=309\&VName=PQD.

17. Doyle W. Classroom organization and management. In: Wittrok M, organizer. Handbook of research on teaching. New York: MacMillan; 1986. p.392-431.

18. Grossman P. Responding to our critics: from crisis to opportunity in research on teacher education. J Teach Educ. 2008;59:10-24.

19. Grossman P, McDonald M. Back to the future: directions for research in teaching and teacher education. Am Educ Res J. 2008;45:184-205. [citado 14 set. 2010]. Disponível em: http://aer.sagepub.com/content/45/1/184.

20. Stran M, Curtner-Smith M. Impact of different types of knowledge on two preservice teachers' ability to learn and deliver the sport education model. Phys Educ Sport Pedag. 2010;15:243-56.

21. Zeichner KM. A formação reflexiva de professores: ideias e práticas. Lisboa: EDUCA; 1993.

22. Hildebrandt R, Laging R. Concepçōes abertas no ensino da educação física. Rio de Janeiro: Ao Livro Técnico; 1986.

23. Soares CL, Taffarel CNZ, Varjal E, Castellani Filho L, Escobar MO, Bracht V. Metodologia do ensino de educação física. São Paulo: Cortez; 1992.

24. Kunz E. Transformação didático-pedagógica do esporte. Ijuí: Unijuí; 1994.

25. Medina JPS. A educação física cuida do corpo... e "mente": bases para a renovação e transformação da educação física. Campinas: Papirus; 1983.

26. Castellani Filho L. Educação física no Brasil: a história que não se conta. Campinas: Papirus; 1988.

27. Betti M. Educação física e sociedade. São Paulo: Movimento; 1991.

28. Kunz E. Educação física: ensino e mudanças. Ijuí: Unijuí; 1991.

29. Universidade Federal de Pernambuco, Universidade Federal de Santa Maria. Grupo de Trabalho Pedagógico. Visão didática da educação física: análises críticas e exemplos práticos de aula. Rio de Janeiro: Ao Livro Técnico; 1991.

30. Resende H. Reflexões sobre algumas contradições da educação física no âmbito da escola pública e alguns caminhos didático-pedagógicos na perspectiva da cultura corporal. Movimento 1994;1:20-8. [citado 3 abr. 2013]. Disponível em: http://seer.ufrgs.br/Movimento/article/view/2005/897.

31. Oliveira AAB. Metodologias emergentes no ensino da educação física. Rev Educ Fís/UEM. 1997;8:21-7. [citado 3 abr. 2013]. Disponível em: http://eduem.uem.br/ojs/index.php/RevEducFis/article/view/3868.

32. Oliveira AAB. Textos pedagógicos sobre o ensino da educação física. Movimento. 2005;11:171-82. [citado 3 abr. 2013]. Disponível em: http://seer.ufrgs.br/Movimento/article/viewFile/13265/7586.

33. Ghiraldelli Júnior P. Educação física progressista: a pedagogia crítico-social dos conteúdos e a educação física brasileira. São Paulo: Loyola; 1998.

34. Bracht V. A constituição das teorias pedagógicas da educação física. Cad Cedes. 1999;19:69-88. [citado 3 abr. 2013]. Disponível em: http://www.scielo.br/pdf/ccedes/v19n48/v1948a05.pdf.

35. Fratti RG. Uma proposta político/pedagógica para a educação física: dificuldades, limites e possibilidades de uma intervenção crítica. Rev Bras Ciênc Esporte. 1999;21:200-7.

36. Hildebrandt-Stramann R. Textos pedagógicos sobre o ensino da educação física. Ijuí: Unijuí; 2001.

37. Furtado IW. Contribuições da educação física como prática pedagógica na formação de sujeitos autônomos [dissertação]. Florianópolis (SC): Universidade Federal de Santa Catarina, Centro de Desportos; 2002. [citado 3 abr. 2013]. Disponível em: http://repositorio.ufsc.br/xmlui/handle/123456789/83930.

38. Nogueira QWC. Educação física e pedagogia crítica: praticar o discurso? Perspectiva. 2003;21:179-97. [citado 3 abr. 2013]. Disponível em: http://150.162.1.115/index.php/perspectiva/article/view/10213/9439.

39. Daolio J. Educação física e o conceito de cultura. Campinas: Autores Associados; 2004.

40. Taffarel CZ, Lacks S, Santos Júnior CL, Carvalho M, D’Agostini A, Titton M, Casagrande N. Formação de professores de educação física para a cidade e o campo. Pensar Prát. 2006;9:153-79. [citado 3 abr. 2013]. Disponível em: http:// www.revistas.ufg.br/index.php/fef/article/view/166/154.

41. Rocha B, Winterstein PJ, Amaral SCF. Interação social em aulas de educação física. Rev Bras Educ Fís Esporte. 2009;23:235-45. [citado 3 abr. 2013]. Disponível em: http://www.scielo.br/pdf/rbefe/v23n3/v23n3a05.pdf.

42. Correia WR. Educação física escolar: entre inquietudes e impertinências. Rev Bras Educ Fís Esporte. 2012;26:171-8. [citado 3 abr. 2013]. Disponível em: http://www.scielo.br/pdf/rbefe/v26n1/a16v26n1.pdf.

43. Ferraz OL, Correia WR. Teorias curriculares, perspectivas teóricas em educação física escolar e implicações para a formação docente. Rev Bras Educ Fís Esporte. 2012;26:531-40. [citado 3 abr. 2013]. Disponível em: http://www.scielo.br/pdf/rbefe/v26n3/18.pdf.

Rev Bras Educ Fís Esporte, (São Paulo) 2013 Out-Dez; 27(4):633-45 • 643 
44. Siedentop D. Ecological perspectives in teaching research. J Teach Phys Educ. 2002;21:427-40.

45. Ramos V, Graça A, Nascimento JV. O conhecimento pedagógico do conteúdo de treinadores de basquetebol: uma proposta de investigação qualitativa com treinadores experientes. $1^{\circ}$ Congresso Internacional de Jogos Desportivos: Olhares e Contextos da Performance - da Iniciação ao Alto Rendimento; 2007; Porto, PT. Porto: Faculdade de Desporto, Universidade do Porto; 2007.

46. Menck P. Didactics as construction of content. J Curriculum Stud. 1995;27:353-71.

47. Amade-Escot C. The contribution of two research programs on teaching content: "pedagogical content knowledge" and "didactics of physical education". J Teach Phys Educ. 2000;20:78-101.

48. Graça A. O conhecimento pedagógico do conteúdo: o entendimento entre a pedagogia e a matéria. In: Gomes PB, Graça A, organizadores. Educação física e desporto na escola: novos desafios, diferentes soluções. Porto: FCDEF-UP; 2001. p.107-20.

49. Mizukami MG. Aprendizagem da docência: algumas contribuições de L. S. Shulman. Rev Educ. 2004;29:1-11. [citado 17 ago. 2009]. Disponível em: http://coralx.ufsm.br/revce/revce/2004/02/a3.htm.

50. Segall A. Revisiting pedagogical content knowledge: the pedagogy of content/the content of pedagogy. Teach Teach Educ. 2004;20:489-504.

51. Veal WR, Makinster JG. Pedagogical content knowledge taxonomies. Electron J Sci Educ. 1999;3:1-16. [citado 22 out. 2009]. Disponível em: http://wolfweb.unr.edu/homepage/crowther/ejse/vealmak.html.

52. Calderhead J. The development of knowledge structures in learning to teach. In: Calderhead J, organizer. Teachers' professional learning. London: Falmer Press; 1988. p.51-64.

53. Carter K. Teachers knowledge and learning to teach. In: Sikula RHMHJ, organizer. Handbook of research on teacher education. New York: MacMillan; 1990. p.291-310.

54. Rovegno I. A participant-observation study of knowledge restructuring in a field-based physical education methods course. Res Q Exerc Sport. 1991;62:205-12.

55. Ennis C. Knowledge and beliefs underlying curricular expertise. Quest. 1994;46:164-75.

56. Carreiro da Costa F. Formação de professores: objectivos, conteúdos e estratégias. In: Carreiro da Costa F, Carvalho LM, Onofre MS, Diniz JA, Pestana C, organizadores. Formação de professores em educação física: concepções, investigação, prática. Lisboa: Edições FMH; 1996. p.9-36.

57. Intrator SM. Beginning teachers and the emotional drama of the classroom. J Teach Educ. 2006;57:232-40.

58. Levin DM, Hammer D, Coffey JE. Novice teachers' attention to student thinking. J Teach Educ. 2009;60:142-55.

59. Marcon D, Graça ABS, Nascimento JV. Estruturantes da base de conhecimentos para o ensino de estudantes-professores de educação física. Motriz: Rev Educ Fís. 2010;16:776-87. [citado 25 ago. 2010]. Disponível em: http://www.periodicos.rc.biblioteca.unesp.br/index.php/motriz/article/view/1980-6574.2010v16n3p776/pdf_53.

60. Wittizorecki E, Molina Neto V, Bossle F. Mudanças sociais e o trabalho docente de professores de Educação Física na escola: estudo a partir de histórias de vida. Movimento. 2012;18:149-69. [citado 28 mar. 2013]. Disponível em: http://seer.ufrgs.br/Movimento/article/view/23894/19308.

61. Molina Neto V. A cultura do professorado de educação física das escolas públicas de Porto Alegre. Movimento. 1997;4:34-42. [citado 28 mar. 2013]. Disponível em: http://seer.ufrgs.br/Movimento/article/view/2365.

62. Wittizorecki E, Molina Neto V. O trabalho docente dos professores de educação física na Rede Municipal de Ensino de Porto Alegre. Movimento. 2005;11:47-70. [citado 28 mar. 2013]. Disponível em: http://seer.ufrgs.br/Movimento/article/view/2861/1475.

63. Wright S. A compatative view of teaching practice in physical education. Int Sports Stud. 1999;21:55-68. [citado 15 set. 2009]. Disponível em: http://www.la84foundation.org/SportsLibrary/ISS/ISS2101/ISS2101f.pdf.

64. Sousa JM. O olhar etnográfico da escola perante a diversidade cultural. Psi: Rev Psicol Soc Inst. 2000;2:107-20.

65. Sena S, Lima JM. O jogo como precursor de valores no contexto escolar. Rev Bras Educ Fís Esporte. 2009;23:247-62. [citado 3 abr. 2013]. Disponível em: http://www.scielo.br/pdf/rbefe/v23n3/v23n3a06.pdf.

66. Marcon D. Construção do conhecimento pedagógico do conteúdo dos futuros professores de educação física [tese]. Porto (PT): Universidade do Porto, Faculdade de Desporto; 2011. [citado 24 jun. 2011]. Disponível em: http:// repositorio-aberto.up.pt/handle/10216/55556.

67. Mondéjar L, Álvarez F. Las preocupaciones docentes de los profesores noveles durante su período de prácticas didácticas. In: Mondéjar L, Álvarez F, organizadores. La enseñanza de la educación física: análisis de las primeras experiencias docentes. Madrid: Editorial Síntesis; 2005. p.143-60.

68. Abell SK, Rogers MAP, Hanuscin DL, Lee MH, Gagnon MJ. Preparing the next generation of science teacher educators: a model for developing PCK for teaching science teachers. J Sci Teach Educ. 2009;20:77-93. [citado 5 jun. 2010]. Disponível em: http://www.springerlink.com/content/a1j4p781335r2548/fulltext.pdf. 
69. Van Driel J, Veal W, Janssen F. Pedagogical content knowledge: an integrative component within the knowledge base for teaching. Teach Teach Educ. 2001;17:979-86. [citado 15 set. 2009]. Disponível em: http://www.sciencedirect. com/science/article/B6VD8-44B1V22-9/2/06dd96179d3688fe73753c36ed37ce96.

70. Bal DL, Forzani FM. The work of teaching and the challenge for teacher education. J Teach Educ. 2009;60:497-512.

71. Behets D, Vergauwen L. Learning to teach in the field. In: Kirk D, MacDonald D, O'Sullivan M, organizers. Handbook of physical education. London: Sage; 2006. p.407-24.

72. Metzler MW, Tjeerdsma BL, Mozen DM. Assessing pedagogical knowledge. J Teach Phys Educ. 2000;19:487-507.

73. Jenkins JM, Veal ML. Preservice teachers' PCK development during peer coaching. J Teach Phys Educ. 2002;22:49-68.

74. McCaughtry N, Rovegno I. Development of pedagogical content knowledge: Moving from blaming students to predicting skillfulness, recognizing motor development, and understanding emotion. J Teach Phys Educ. 2003;22:355-68.

75. Wiegand RL, Bulger SM, Mohr DJ. Curricular issues in physical education teacher education. J Phys Educ Recr Dance. 2004;75:47-56.

76. Zeichner KM. Rethinking the connections between campus courses and field experiences in college-and universitybased teacher education. J Teach Educ. 2010;61:89-100.

77. Marcon D, Graça ABS, Nascimento JV. Critérios para a implementação de práticas pedagógicas na formação inicial em Educação Física e implicações no conhecimento pedagógico do conteúdo dos futuros professores. Rev Bras Educ Fís Esporte. 2011;25:497-511. [citado 18 out. 2011]. Disponível em: http://www.scielo.br/pdf/rbefe/v25n3/v25n3a13.pdf .

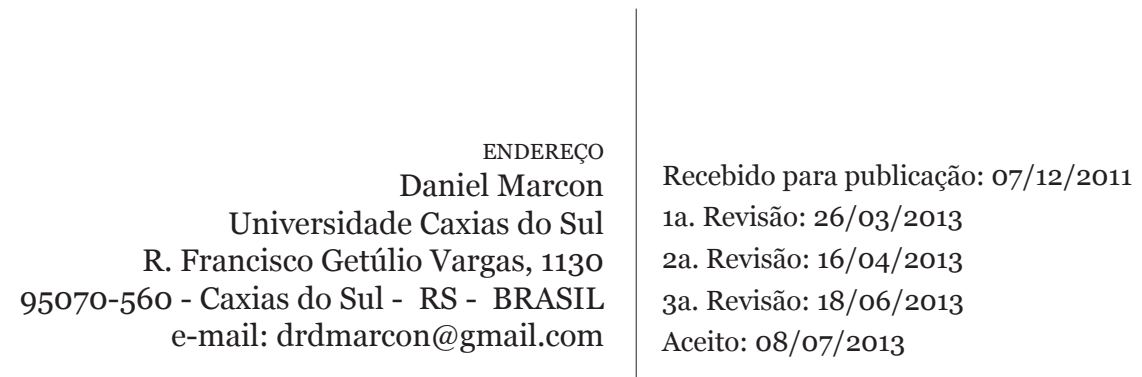

Rev Bras Educ Fís Esporte, (São Paulo) 2013 Out-Dez; 27(4):633-45 • 645 